\title{
A Development Model of Organizational Culture Management Systems for Private Schools in the Isan Region of Thailand
}

\author{
Jaturong Pongsiri ${ }^{1}$, Songkoon Chantachon ${ }^{1} \&$ Kosit Phaengsoi ${ }^{1}$ \\ ${ }^{1}$ The Faculty of Cultural Science, Mahasarakham University, Khamriang Sub-District, Kantarawichai District, \\ Maha Sarakham, Thailand \\ Correspondence: Jaturong Pongsiri, 414 Moo 2, Pongsiri Road, Dankuntod Sub-district, Dankuntod District, \\ Nakhon Ratchasima, 30210, Thailand. E-mail: rattiya_2513@hotmail.com
}

$\begin{array}{lc}\text { Received: May 10,2013 Accepted: May 27, } 2013 \quad \text { Online Published: August 1, } 2013 \\ \text { doi:10.5539/ass.v9n10p56 } & \text { URL: http://dx.doi.org/10.5539/ass.v9n10p56 }\end{array}$

\begin{abstract}
Northeastern private schools are an important part of the Thai education system. This qualitative research assesses the background of, current conditions in and problems with organizational culture management systems for private schools in the Isan region of Thailand. The information found that most private schools use an achievement cultural model and that the management system of private schools is in four areas: a) academic management; b) human resources management; c) budget management; d) information or general management. However, private schools are placed at a disadvantage to government schools by their lack of unified management, causing the levels of efficiency and student quality to suffer. This research outlines a development model to help create a private school management system with more efficiency, which will raise the level of quality education that students receive.
\end{abstract}

Keywords: development, model, system, organization, culture, private school

\section{Introduction}

Administration and management are important factors in work that lead to the success of aims and allow an institution or organization to efficiently attain their objectives. Directors must be responsible for planning, organizing, staffing, directing, coordinating, reporting and budgeting (Ketwong, 1998, pp. 7-8). Considering that organization is one aspect of management, various establishments must develop their 'organizational culture', regardless of whether they are private or government institutions (Nopkun, 1998, pp. 46-52).

Organizational culture is an important method for promoting efficient management. It is also a point of entry for wide understanding and reflects the outlook and work of the organization. Woranat Saengmanee (2001, p. 165) suggested that organizational culture has a minimum of two responsibilities. The largest is the gathering of members so that they are united, know their methods of work and have contact with one another to promote their mutual relationships and sense of attachment. This also includes the creation of an organizational identity for instilling pride in the group. The second responsibility is to help the organization quickly adapt to different environmental conditions in its vicinity. Krit Seubson (1995, pp. 8-11) concluded that organizational culture has five components, which are the environment and surroundings of the organization, values, idols, customs and cultural sphere. Management is also related to organizational culture, as it encompasses the components of belief, symbolism and ceremony (Dill, 1982, p. 303). Chaffee and Tierney (1988, pp. 70-71) proposed six components for the study of organizational culture, which were environmental conditions, duties, social discipline, information, strategies and leadership. These components are not absolutely separate and have an overlapping relationship. As a result, culture is a collective organ, organizational component and has various contexts.

Private schools are able to relieve the governmental burden of responsibilities. They must accelerate the improvement of administrative management in order to conform to the policies of the Royal Acts and provide a viable option for the people. To achieve this, there must be creative characteristics of management that are efficient, strong, ensure successful academic results that meet the expectations of parents and guardians and correspond to reform policies. This also causes efficient implementation of future activities. The adaptation of administrative management in private schools is necessary and cannot be avoided. However, this does not mean that everything will be altered, as each individual school has its own background and identity. Therefore, it is important to study current management conditions and problems in order to establish a method for improvement 
that is suitable for each school. Parents and guardians who send their children to reputable and famous schools believe that these institutions will instruct their students to be good people and succeed on an academic level, according to their objectives. The parents and guardians will set the aims of strong morality and social awareness for their children.

Given these issues, the researchers wanted to study famous educational establishments to determine the form of culture for creating students in the model of social requirements. This research delves into the culture of educational institutions to reveal the method of management behind creation of the institutional culture. Although each academic institution has different abilities and contexts, the same procedural methods or applications may be used for a number of activities, depending on the suitability of the method for the school. Therefore, the researchers were interested in studying a development model of organizational culture management systems for private schools in the Isan region of Thailand that belong to the Office of the Private Education Commission (OPEC). This study will help the development of private schools so that they retain and improve their level of quality for the future.

\section{Research Aims}

This research has three primary aims: a) to study the background and history of organizational culture management systems for private schools in the Isan region of Thailand; b) to study the current conditions of and problems with organizational culture management systems for private schools in the Isan region of Thailand; c) to study a development model of organizational culture management systems for private schools in the Isan region of Thailand.

\section{Research Methodology}

This study is a qualitative research. The sample population was selected using a purposive sampling technique in three provinces of Northeastern Thailand (Isan), which included school directors, teachers, parents and guardians. The study area was comprised of schools in the fourth and fifth primary education areas of Nakhon Ratchasima Province, the first primary education area of Khon Kaen Province and the first primary education area of Udon Thani Province. The informants were separated into three groups, which were key informants, casual informants and general informants. The number of informants totaled one-hundred and thirty-five.

Six research tools were used for data collection. A survey was the first method of collecting school data in the educational areas. The survey concerned the surrounding conditions of the organization, attitudes, beliefs, popularity and customs. These individuals were directors, teachers, students, parents and guardians. The second tool was document analysis. This was another preliminary research technique used to assess overall conditions, staff data, management creation, mandatory regulations, work plan, programs and historical background of the school. The third tool was participatory field observation. The researchers entered the field of study and made notes on observations, including taking photographs, sound clips and video recordings. The fourth method of research was interview. The informants who provided data for the survey were interviewed on the development of organizational culture management systems for private schools. The fifth tool was a focus group to solve problems and discuss prominent or confusing aspects of data collection. The participants of the focus group were key informants and 8-10 casual informants. The final method of data collection was a workshop, attended by representatives of each informant group to conclude the research into a development model of organizational culture management systems for private schools in the Isan region of Thailand.

A qualitative technique was used for inductive data analysis, categorization of data and comparisons.

\section{Results}

4.1 The Background and History of Organizational Culture Management Systems for Private Schools in the Isan Region of Thailand

It was found that most private schools use an achievement cultural model, as management in the majority of private schools is dependent upon the importance of directors. The directors are those people with the highest level of ability in the schools and are responsible for a number of different tasks throughout the school. They conduct their work in an orderly and efficient fashion, which enables them to achieve success in their various roles. Directors will aim to achieve success in their work through the system of organizational culture in the school. This culture outlines the philosophy, vision, obligation and procedure of work, including the management aims and prominent policies of the school, in order to promote the importance of student quality, discipline, virtue and morality, as well as the adherence of all students and teachers to school regulations. The researchers analyzed the data from nine schools and studied related documents to conclude that the management system of private schools following the national education management systems of OPEC has four sides: a) academic 
management; b) human resources management; c) budget management; d) information or general management. In each school, different names will be used to refer to management. These are determined by the context and responsibility of the managers in each school. The overall image of management in each school is similar.

4.2 The Current Conditions of and Problems with Organizational Culture Management Systems for Private Schools in the Isan Region of Thailand

Directors in the majority of schools have improved the system in their institutions by incorporating the collective view. This is an improvement because a management system with a sole participant is likely to have a narrow perspective and collective opinion adds quality to the school. The advantage of a management system with a committee is the alteration of perspectives through collective experience. Directors of private schools in Isan have the power to directly influence the quality of management because schools that are managed efficiently and with quality depend upon the setting of management objectives and obligations by the directors. The directors must have skills of leadership, creativity, responsibility and humanity. They must generate a positive reputation for their school and act as good role models. The directors must also be able to delegate according to knowledge and ability, provide opportunities for colleagues to voice their opinions, encourage cooperation in the decision-making process, solve problems, promote teamwork, make suggestions to and take care of colleagues, and regularly appraise their staff.

Study of the problems with organizational culture management systems in private schools of the Isan region found that the majority of power lies with the directors. There are sub-management levels with power distributed by the director. The director is skilled at entrusting power and responsibility but the teachers entrusted are indecisive because they are not given absolute and final decision making power. Employees of the schools are not prepared to give their opinions on working procedure. The majority of employees prefer to be led than lead and they generally feel that decision making is the responsibility of the director. Employees in the schools studied lack confidence and fear making mistakes. Workers place more importance on the success of work than the procedure and do not pre-plan their work. Schools have clear identities but the directors do not fully exploit these to benefit the management of the school. Activities organized by the schools do not correspond to the school philosophy as much as they should because of the limited time constraints. Aside from this, the system of evaluation lacks efficiency and is thus disconnected from the philosophy. Schools have extremely strict regulation systems that make new teachers reluctant to stay for long periods of time. The majority of employees lives in the immediate vicinity of the school and does not want to work elsewhere. They stay in the school for a long time, which breeds familiarity. The schools are within the communities and are near large, busy roads. This poses a danger for students. Transportation of students to and from school causes traffic congestion in front of the schools and inconveniences for parents and guardians. The number of buildings, classrooms and other facilities is unsuitable for the number of students. The sports field and other conveniences must be improved. Additionally, information should be made sufficiently efficient, so that the data can be fully used in education.

\subsection{A Development Model of Organizational Culture Management Systems for Private Schools in the Isan} Region of Thailand

There must be focus on the organizational culture management systems for private schools in the Isan region of Thailand using four characteristics. These are adaptive culture, achievement culture, ancestral culture and bureaucratic culture. The management of schools has four components, which are academic management, human resources management, budget management and general management. Organizational culture management has seven components, which are surrounding conditions and environment of the school, leadership, management strategy, dissemination and use of information, mandatory school regulations, behavioral conduct for members of the organization and employee cooperation. These components are aimed at developing efficiency and student quality and comprise a method of promoting the quality of education management of private schools in the Isan region. Educational institutes can use this method to benefit the future development of private schools in Isan.

\section{Discussion}

The findings of research into the background of organizational culture management systems for private schools in the Isan region of Thailand found that the director is the most important figure in the system. The majority of schools have an achievement culture system. This corresponds to the research of Richard Daft (1999, pp. 193-195), which suggested that achievement culture has a clear vision for its organizational objectives and leaders emphasize the attainment of specific, clear results. Organization generates awareness of maintenance, which the directors translate to their surrounding environment at the cost of flexibility and fast adaptation. This culture is a desired result which gives value to competition, work and initiatives of the employees in order to achieve the goals, emphases and desires in unifying the organization. Organizations that respect achievement 
culture harness values of aggressive competition, the abilities of employees and long-term work satisfaction until the successful fulfillment of original organizational objectives. The desire for success is like glue connecting each individual in the organization. Many companies that have an achievement culture will place importance upon competition and drive for success. The workers with good work results will receive high rewards and those who do not meet the aims will be asked to leave the organization.

The results of study into the current conditions of organizational culture management systems for private schools in the Isan region of Thailand correspond with the research of Mallika Manochompoo (2004, p. 76), which found that directors of educational institutes are leaders. Directors have a creative mind and sense of responsibility. They provide suggestions and recommendations to others at work. Directors are trustworthy, take care of their employees and regularly provide appraisals. Directors have good human qualities and delegate in the workplace, according to the abilities of the workers. Directors solve the problems in educational institutes by encouraging cooperation. Only a small minority of directors does not fit this case and is unsure of its procedural duties. Slightly over half of all employees studied in Manochompoo's work attested that directors would encourage them in the event of a mistake. Aside from this, the results also correspond to the work of Witoon Jaemkling (2004, p. 268). Jaemkling studied the necessary behavioral characteristics of directors in private schools and discovered that directors of private schools have a strong work-ethic, have high working standards and are prepared to adapt and improve the organization and its employees. These directors adhere to data protection standards, are secure and are consistent in their work, including the quality of education.

The problems found in this research were in line with those discovered in the work of Patriya Jarong (2009, p. 115). Jarong found that one management problem in private schools was the distribution of power, particularly agreement of distribution among general teachers. This is because of familiarity with the all-encompassing management system whereby orders are taken solely from directors. This causes problems with the distribution of management authority, especially for teachers with limited experience in general private schools. This is due to the fact that the majority of teachers with ability and experience will take tests to become a government official or employee. General private schools thus lack this type of employee and only newly qualified teachers, lacking skill, expertise and teaching experience remain.

The model outlined in this result corresponds to the research of Sathe $(1985$, p. 245), which identified seven aspects of organizational culture management as follows: a) cooperation within the organization cannot occur from orderly regulations and can only be genuine cooperation; b) cultural decision-making affects the decision making process due to the belief and values that cause initial principles and inclination towards stability within the organization. This affects the efficiency of decision-making; c) control is the ability to ensure that work procedures achieve the desired pre-defined aims; d) inaccurate communication is principally caused by problems of misinformation and distortion of the truth. Importantly, if the level of confusion of the information is higher, the potential mistakes will be higher; e) employee relationships will give feeling to the organization, when there is cooperation and experience, which causes loyalty to the organization; f) recognition of culture is the condition for recognition of various situations and procedures within the organization; g) culture helps organization members to use claims as a reason for their behavior.

\section{References}

Chaffee, E. E., \& Tierney, W. G. (1988). Collegiate culture and leadership strategies. New York: Macmillan.

Daft, R. L. (1999). Leadership: theory and practice. USA: Dryden Press.

Dill, D. D. (1982). The management of academic culture: note on the management of meaning and social integration. Higher Education, 11, 303-320. http://dx.doi.org/10.1007/BF00155621

Ketwong, A. (1998). Planning principles and techniques. Bangkok: Thammasat University.

Nopkun, S. (1998, May-June). How is organizational culture important? Government Officer Journal, 43(3), 47.

Saengmanee, W. (2001). Organization and management. Bangkok: Rabieblong Publishers.

Sathe, V. (1985). Culture and related corporate realities. Illinois: Irwin.

Seubson, K. (1995). Educational culture and behavior in organization. Bangkok: Chulalongkorn University Publishers.

\section{Copyrights}

Copyright for this article is retained by the author(s), with first publication rights granted to the journal.

This is an open-access article distributed under the terms and conditions of the Creative Commons Attribution license (http://creativecommons.org/licenses/by/3.0/). 